\title{
Survey on Student Attendance System based on Data Analytics
}

\author{
Prof. S. Y. Inamdar ${ }^{1}$, Divya M. Aswani ${ }^{2}$ \\ Assistant Professor, Department of Computer Science and Engineering, AGTI'S DACOE, Karad, India ${ }^{1}$ \\ Student, Department of Computer Science and Engineering, AGTI'S DACOE, Karad, India ${ }^{2}$
}

\begin{abstract}
As Attendance is mandatory in every schools and colleges we developed Student Attendance System Based on Data Analytics which is developed with both web interface and mobile application. With the help of web interface admin registers the authorized faculty to the system. Mobile application is used by faculty to take attendance with the help of a smart phone and save it to the server. Admin has the privileges to view the attendance uploaded by the faculty, to make any changes in the attendance and finally generate the report and also maintain database.
\end{abstract}

Keywords: Data Analytics, Mobile application, Web interface, Internet.

\section{INTRODUCTION}

Student Attendance system based on Data Analytics is a Apart from that, ${ }^{[2]}$ biometrics technology is used for project where the attendance is taken and maintained attendance reporting and tracking. Most of the biometrics digitally without any involvement of paper work. In this technology use thumb scanner. This allows a fair and system we have two main modules: admin and faculty. reliable attendance to be recorded. Fingerprint peripheral Admin module does the work of registering the faculty is used to record the attendance and sent the data into members so as to avoid any unauthorized access to the system using wireless or wired technology. However, it system. The registered faculty signup to the system with requires fingerprint peripheral which incurs cost; in case its unique username and password to mark the attendance of hardware failure the whole attendance has to be taken of students and submits it to the database. The attendance manually.

can also be stored in phone's internal or external memory in case of server failure. Faulty can view the attendance date wise, subject wise, session wise. Admin can view and also can edit the attendance. Reports can be generated here by only admin in just single clicks. Admin uses the web interface and faculty uses mobile application. This web interface is developed to run on different platforms and the application provided can be installed and run on all Smartphone.

\section{BACKGROUND AND MOTIVATION}

There are various educational institutions that use ${ }^{[1]}$ Radio Frequency Identification and Detection (RFID) technology to record their student's attendance. In this RFID reader and RFID chips are used. Reader is located on fixed location sends signal to passive RFID chip detected in range of reader. Chip re-transmits the acknowledgement signal with its unique Identifier code, hence chip is identified. Also, a single reader can identify many numbers of chips in very short period of time.

However, RFID technologies incur cost of providing each individual with RFID card that has chip implemented. RFID reader should be sufficiently enough to capture each RFID chips acknowledgement. In case there are different departments within same infrastructure each RFID reader should detect RFID chip uniquely according to respective department, which could be cumbersome.

\section{III.RELATED WORK}

Student Attendance system based on Data Analytics focuses mainly on taking attendance and generating report in minimal time. Report generation is done using data analysis tool. Zeppelin is the tool which is used for analysis. As said before there are two modules: admin and faculty. Admin's are Head of Department of the various departments who are the persons to get access to the system through web interface. Admin has the privilege to register the authorized faculty to the database. Once registration is done, faculty can take attendance and upload it, which will be saved to the database. All the faculty needs is a Smartphone and an Internet connection to upload the attendance to database. In case of server failure or no Internet connection at moment faculty can save the taken attendance to phone's memory to upload it later.

Faculty's work is done here. Admin further views the attendance according to the year, semester, student or time. If admin has to do any changes to the uploaded attendance by the faculty then he/she has these privileges here to change it with the help of faculty. Later the report generation which is usually done manually and then later it is submitted to admin in paper form is done in this system with just single click; no need to do tedious calculation or sit for hours to generate excel reports. 


\section{IV.ARCHITECTURE}

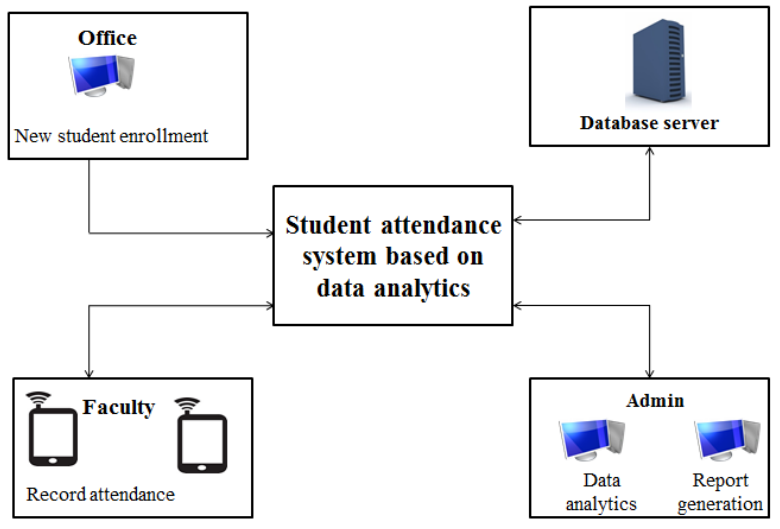

Fig.1Architecture of proposed system

\section{REFERENCES}

[1] Pushpa S. Gagare., Priyanka A. Sathe, Vedant T. Pawaskar., Sagar S. Bhave, "Smart Attendance System", International Journal on Recent and Innovation Trends in Computing and Communication, January 2014

[2] KarthikKrishnamurthi, S. Irudaya Mary, B. N. Sumalatha3 Adler Pereira, "Fingerprint Based Attendance System", International Journal of Advanced Research in Computer and Communication Engineering Vol. 4, Issue 3, March 2015. 